\title{
Impact of age on leptin and adiponectin independent of adiposity
}

\author{
Britta Schautz ${ }^{1}$, Wiebke Later ${ }^{1}$, Martin Heller ${ }^{2}$, Achim Peters ${ }^{3}$, Manfred J. Müller ${ }^{1}$ \\ and Anja Bosy-Westpha1 ${ }^{1 *}$ \\ ${ }^{1}$ Institut für Humanernährung und Lebensmittelkunde, Christian-Albrechts Universität zu Kiel, Düsternbrooker Weg 17-19, \\ D-24105 Kiel, Germany \\ ${ }^{2}$ Clinic for Diagnostic Radiology, University Medical Center Schleswig-Holstein, Kiel, Germany \\ ${ }^{3}$ Medical Clinic I, University of Luebeck, Luebeck, Germany
}

(Submitted 23 March 2011 - Final revision received 14 September 2011 - Accepted 14 September 2011 - First published online 28 February 2012)

\section{Abstract}

Age-related changes in leptin and adiponectin levels remain controversial, being affected by inconsistent normalisation for adiposity and body fat distribution in the literature. In a cross-sectional study on 210 Caucasians (127 women, eighty-three men, 18-78 years, BMI $16 \cdot 8-46 \cdot 8 \mathrm{~kg} / \mathrm{m}^{2}$ ), we investigated the effect of age on adipokine levels independent of fat mass (FM measured by densitometry), visceral and subcutaneous adipose tissue volumes (VAT and SAT assessed by whole-body MRI). Adiponectin levels increased with age in both sexes, whereas leptin levels decreased with age in women only. There was an age-related increase in VAT (as a percentage of total adipose tissue, VAT\%TAT), associated with a decrease in $\mathrm{SAT}_{\text {legs }} \% \mathrm{TAT}$. Adiposity was the main predictor of leptin levels, with $75 \cdot 1 \%$ of the variance explained by $\% \mathrm{FM}$ in women and $76.6 \%$ in men. Independent of adiposity, age had a minor contribution to the variance in leptin levels $(5.2 \%$ in women only). The variance in adiponectin levels explained by age was $14.1 \%$ in women and $5.1 \%$ in men. In addition, independent and inverse contributions to the variance in adiponectin levels were found for truncal SAT (explaining additional $3 \cdot 0 \%$ in women and $9.1 \%$ in men) and VAT\%TAT (explaining additional $13.0 \%$ in men). In conclusion, age-related changes in leptin and adiponectin levels are opposite to each other and partly independent of adiposity and body fat distribution. Normalisation for adiposity but not for body fat distribution is required for leptin. Adiponectin levels are adversely affected by subcutaneous and visceral trunk fat.

\section{Key words: Body fat distribution: Fat mass: Ageing: Leptin: Adiponectin}

Ageing is associated with an increase in fat mass (FM) and a redistribution of adipose tissue from peripheral to central fat depots $^{(1)}$. The age-related decrease in the capacity of the body to store fat in subcutaneous depots (SAT) ${ }^{(2)}$ increases fat deposition in visceral adipose tissue (VAT), enhancing the risk of CVD and type 2 diabetes $^{(3)}$. The age-related decrease in gluteofemoral SAT may also add to adverse health consequences because this depot is inversely associated with insulin resistance $^{(4)}$ and cardiometabolic risk ${ }^{(5)}$. By contrast, epidemiological data suggest a lower impact of overweight and obesity on mortality with age ${ }^{(6)}$. Age-related changes in the metabolic, endocrine and inflammatory function of adipose tissue may contribute to this contradiction. Adiponectin is an anti-inflammatory adipokine, which is positively associated with insulin sensitivity ${ }^{(7)}$, whereas leptin has been found to be related to insulin resistance, inflammation and haemostasis $^{(8)}$. The effect of age on serum levels of these adipokines remains controversial. Some studies have shown an increase in leptin levels with age ${ }^{(9)}$, whereas others found no effect or even an age-related decrease in serum leptin concentrations $^{(10-13)}$. In addition, adiponectin levels increased ${ }^{(14,15)}$ or remained unchanged with age ${ }^{(16)}$. These discrepant findings may be partly due to differences in the assessment of adiposity used for the normalisation of adipokine levels. Although leptin is mainly secreted by SAT ${ }^{(17)}$, leptin levels were either not normalised ${ }^{(9)}$ or adjusted for $\% \mathrm{FM}^{(12,13,18)}$. Adiponectin inversely correlated with \%FM as well as with VAT, but was adjusted for these parameters only in some ${ }^{(12,15,16)}$, but not all studies ${ }^{(9,14)}$.

In addition, methodological issues of body composition analysis may contribute to discrepancies in the normalisation of adipokine levels ${ }^{(19)}$. For example, leptin levels were highly correlated with \%FM measured by dual-energy X-ray absorptiometry, whereas bioelectrical impedance-derived

Abbreviations: FM, fat mass; HOMA-IR, homeostasis model assessment-insulin resistance; SAT, subcutaneous adipose tissue volume; SAT arms, subcutaneous adipose tissue volume of the arms; $\mathrm{SAT}_{\text {legs }}$, subcutaneous adipose tissue volume of the legs; $\mathrm{SAT}_{\text {total }}$, subcutaneous adipose tissue volume of the total body; $\mathrm{SAT}_{\text {trunk, }}$, subcutaneous adipose tissue volume of the trunk; TAT, total adipose tissue volume; VAT, visceral adipose tissue volume.

*Corresponding author: Dr A. Bosy-Westphal, fax +49431 8805679, email abosyw@nutrfoodsc.uni-kiel.de 
FM showed a weak relationship with leptin only in obese subjects $^{(19)}$.

Because adipokine levels and age are both associated with body fat and fat distribution ${ }^{(20)}$, detailed body composition analysis is a prerequisite for understanding the age-related changes in adipokine levels. Today, whole-body MRI is considered as a 'gold standard' for the analysis of adipose tissue distribution.

The purpose of the present study was (1) to investigate the impact of age on serum leptin and adiponectin levels independent of age-related changes in adiposity and body fat distribution and (2) to determine the effect of leptin and adiponectin on indices of glucose metabolism in a sample of 210 Caucasians aged $18-78$ years.

\section{Subjects and methods}

The study population consisted of 210 healthy Caucasian volunteers (127 women and eighty-three men) aged 18-78 years with a BMI range of $16 \cdot 8-46 \cdot 8 \mathrm{~kg} / \mathrm{m}^{2}$. Participants were recruited from staff at the University of Kiel, by notice board postings in local supermarkets and pharmacies and advertisements in local newspapers. Exclusion criteria were metallic implants, smoking, pregnancy, acute or chronic illness (e.g. diabetes) and regular intake of drugs. The study was conducted according to the guidelines laid down in the Declaration of Helsinki and all procedures involving human subjects were approved by the local ethical committee of the Christian-Albrechts-Universität zu Kiel. Written informed consent was obtained from all subjects before participation.

\section{Study protocol}

All participants arrived at the Body Composition Laboratory of the Institute of Human Nutrition and Food Science in the morning at 07.30 hours after an overnight fast of $>8 \mathrm{~h}$.

\section{Anthropometric measurements}

Body height was measured to the nearest $0.5 \mathrm{~cm}$ with subjects wearing no shoes (Seca stadiometer; Vogel \& Halke, Hamburg, Germany). Weight was assessed to the nearest $0 \cdot 01 \mathrm{~kg}$ with an electronic scale (Tanita, Tokyo, Japan).

\section{Air-displacement plethysmography}

$\%$ FM was assessed using the BOD-POD ${ }^{\mathrm{TM}}$ device (Life Measurement Instruments, Concord, CA, USA). Before each measurement, a two-step calibration was carried out. In the first step, the volume of the empty chamber was measured, and in the second step, the volume of a 50-litre calibration cylinder was assessed. Then, two repeated measurements of body volume were performed, averaged and corrected for predicted body surface area and measured thoracic gas volume using BOD-POD ${ }^{\mathrm{TM}}$ software (version 1.69; Life Measurement Instruments). \%FM was calculated from body mass and volume via body density ${ }^{(21)}$.
$M R I$

Adipose tissue (SAT and VAT) was measured using wholebody multislice MRI. Scans were obtained with a $1.5 \mathrm{~T}$ scanner (Magnetom Vision Siemens, Erlangen, Germany). Subjects were placed on the platform with their arms extended above their heads. The protocol involved the acquisition of approximately 100 axial images of $10 \mathrm{~mm}$ thickness and $10 \mathrm{~mm}$ interslice gaps across the whole body. Images were obtained using a T1-weighted gradient-echo sequence (time to repeat $575 \mathrm{~ms}$, time to echo $15 \mathrm{~ms}$ ). Images were analysed from the wrist to the ankle using SliceOmatic image analysis software (version 4.3; Tomovision, Montreal, Canada). SAT arms was segmented from the wrist to the humeral heads, $\mathrm{SAT}_{\text {legs }}$ from the femoral heads to the ankle and $\mathrm{SAT}_{\text {trunk }}$ was defined as the area between the femoral heads and the humeral heads. VAT was segmented from the top of the liver to the femoral heads. Intra-observer $\mathrm{CV}$ based on the comparison of repeated segmentations were $0.9 \%$ for SAT and $1.0 \%$ for VAT. Body fat distribution is characterised by presenting volumes of adipose tissue as a percentage of total adipose tissue volume (TAT).

Adipocytes are known to enlarge with obesity ${ }^{(22)}$. Because hypertrophic adipocytes have been shown to secrete more leptin and less adiponectin than small adipocytes ${ }^{(23)}$, we used the parameter FM (kg)/total adipose tissue volume as a measure of fat storage (i.e. a proxy for adipocyte size) in adipose tissue.

\section{Adipokines and parameters of glucose metabolism}

Blood samples were taken after an $8 \mathrm{~h}$ overnight fast and analysed following standard procedures. HDL-cholesterol was assessed enzymatically using a Konelab-20i-Analyzer (intra-assay $\mathrm{CV}<3.5 \%$; Konelab, Espoo, Finland). Serum glucose was analysed enzymatically with a Konelab-TestKit (intra-assay $\mathrm{CV}=2 \cdot 2 \%$; Thermo Clinical Labsystems, Frankfurt, Germany). RIA were used to measure serum insulin (CV $<5.4 \%$; Adaltis, Freiburg, Germany), serum leptin and adiponectin concentrations (Linco Research, St Charles, MO, USA). Intra-assay CV were 4-8\% (leptin) and 2-7\% (adiponectin). Insulin resistance was calculated using the $\operatorname{HOMA}^{(24)}$.

\section{Statistical analysis}

Statistical analyses were performed using SPSS for Windows 15.0 (SPSS, Inc., Chicago, IL, USA). Data are presented as means and standard deviations. Levels of adipokines, insulin and HOMA, HOMA-insulin resistance (HOMA-IR) were not normally distributed (Kolgorov-Smirnov test), so these variables were ln-transformed before correlation and regression analyses. Volumes of VAT and SAT by MRI are expressed as a \%TAT in order to characterise fat distribution. Pearson's correlation coefficients were used to calculate the relationships between variables. Differences between sexes were analysed by the independent-samples $t$ test. Partial correlations were used to calculate the relationships between 
variables independent of \%FM, VAT\%TAT and age. Stepwise linear regression analyses were used to determine the relationships between levels of adipokines, age, \%FM and body fat distribution. All variables, which correlated with the levels of leptin or adiponectin, were used as potential confounders for the multiple regression models.

Although all measures of body fat distribution were highly correlated with each other, collinearity diagnostics indicated that they could be used in the same multiple regression model (tolerance values ranging from 0.273 to 1.000). All tests were two-tailed and a $P$ value $<0.05$ was accepted as the limit of significance.

\section{Results}

\section{Subject characteristics}

Characteristics of the study population are given in Table 1. Men were significantly older and had higher body weight, height, VAT and glucose levels compared with women. By contrast, body FM, amounts of total and regional SAT and fat storage in adipose tissue (as assessed by the ratio FM:TAT) were lower in men compared with women. In addition, serum levels of leptin, adiponectin and insulin were also lower in men than in women. Leptin and adiponectin were inversely correlated in men $(r-0.39, P<0.001)$ and women $(r-0 \cdot 26, P=0 \cdot 004)$.

\section{Impact of age and adiposity on leptin and adiponectin levels}

Leptin levels were inversely associated with age in women but not in men (Fig. 1; Table 2). When excluding older women ( $\geq 60$ years), this correlation was confirmed $(r-0 \cdot 23$, $P<0.05)$. Partial correlation adjusted for $\% \mathrm{FM}$ revealed an inverse relationship between age and leptin levels already in the younger age group (18-45 years; $r-0.22, P<0.05)$.

Age was positively associated with VAT\%TAT and inversely with $\mathrm{SAT}_{\text {total }} \% \mathrm{TAT}$ and $\mathrm{SAT}_{\text {legs }} \% \mathrm{TAT}$ in men and women. \%FM correlated with age in men only (Table 2, correlation coefficients). Controlling for $\% \mathrm{FM}$, the inverse association between leptin and age was confirmed in women, whereas in men, the relationship remained non-significant $(P=0.09$; Table 2). Fat storage in adipose tissue (FM:TAT) adjusted for \%FM was associated with age in women only (Table 2, partial correlation coefficients). Fat storage in adipose tissue correlated with \%FM ( $r 0.70$ in women, $r 0.76$ in men, both $P<0.001)$ and levels of leptin in both sexes (Table 3).

Unadjusted leptin levels as well as levels of leptin adjusted for age correlated with \%FM, regional SAT depots, VAT, $\mathrm{SAT}_{\text {trunk }} \% \mathrm{TAT}$ and FM:TAT, and were inversely associated with $\mathrm{SAT}_{\text {arms }} \% \mathrm{TAT}$ and $\mathrm{SAT}_{\text {legs }} \% \mathrm{TAT}$ in both sexes. In men, leptin levels also correlated with VAT\%TAT (Table 3).

Age explained $5 \cdot 2 \%$ of the variance in leptin levels in women (Table 4 , model 1 ). In a stepwise regression analysis with serum leptin as a dependent variable and age, \%FM,

Table 1. Anthropometric variables, body composition, levels of adipokines and parameters of glucose metabolism in the study population stratified by sex ( $n 210)$ (Mean values and standard deviations)

\begin{tabular}{|c|c|c|c|c|c|}
\hline & \multicolumn{2}{|c|}{ Women ( $n$ 127) } & \multicolumn{2}{|c|}{ Men ( $n$ 83) } & \multirow[b]{2}{*}{$P^{*}$} \\
\hline & Mean & SD & Mean & SD & \\
\hline Age (years) & 38.1 & 13.9 & 43.9 & $15 \cdot 9$ & $<0.001$ \\
\hline Height (m) & 1.68 & 0.07 & 1.78 & 0.06 & $<0.001$ \\
\hline Weight (kg) & $80 \cdot 7$ & $21 \cdot 2$ & $87 \cdot 3$ & $16 \cdot 0$ & 0.012 \\
\hline BMI $\left(\mathrm{kg} / \mathrm{m}^{2}\right)$ & 28.4 & $6 \cdot 8$ & $27 \cdot 4$ & 4.6 & 0.203 \\
\hline FM (\% body weight) & 37.9 & $10 \cdot 7$ & $23 \cdot 3$ & $8 \cdot 6$ & $<0.001$ \\
\hline $\mathrm{FM}(\mathrm{kg})$ & $32 \cdot 3$ & $16 \cdot 1$ & $21 \cdot 3$ & $10 \cdot 8$ & $<0.001$ \\
\hline $\mathrm{SAT}_{\text {total }}$ (litres) & $31 \cdot 2$ & $14 \cdot 1$ & $19 \cdot 4$ & $7 \cdot 3$ & $<0.001$ \\
\hline SAT trunk (litres) & $14 \cdot 3$ & $7 \cdot 1$ & $9 \cdot 3$ & $4 \cdot 2$ & $<0.001$ \\
\hline $\mathrm{SAT}_{\text {arms }}$ (litres) & 3.3 & 1.4 & $2 \cdot 4$ & 0.8 & $<0.001$ \\
\hline $\mathrm{SAT}_{\text {legs }}$ (litres) & $13 \cdot 6$ & $6 \cdot 2$ & $7 \cdot 7$ & $2 \cdot 8$ & $<0.001$ \\
\hline VAT (litres) & $2 \cdot 2$ & 1.3 & 4.6 & 2.5 & $<0.001$ \\
\hline FM:TAT (kg/l) & 0.95 & $0 \cdot 12$ & 0.86 & 0.21 & $<0.001$ \\
\hline $\mathrm{SAT}_{\text {total }} \% \mathrm{TAT}$ & $93 \cdot 2$ & $3 \cdot 7$ & 81.5 & $7 \cdot 7$ & $<0.001$ \\
\hline $\mathrm{SAT}_{\text {trunk }} \% \mathrm{TAT}$ & $41 \cdot 8$ & $6 \cdot 0$ & 38.0 & 5.9 & $<0.001$ \\
\hline $\mathrm{SAT}_{\text {arms }} \% \mathrm{TAT}$ & $10 \cdot 1$ & $2 \cdot 1$ & $10 \cdot 5$ & 1.9 & 0.125 \\
\hline $\mathrm{SAT}_{\text {legs }} \% \mathrm{TAT}$ & $41 \cdot 3$ & $6 \cdot 8$ & 33.0 & $6 \cdot 9$ & $<0.001$ \\
\hline VAT\%TAT & $6 \cdot 8$ & $3 \cdot 7$ & 18.5 & $7 \cdot 7$ & $<0.001$ \\
\hline Glucose (mmol/l) & $5 \cdot 2$ & 0.6 & $5 \cdot 6$ & 0.5 & $<0.001$ \\
\hline Insulin $(\mathrm{mmol} / \mathrm{l}) \dagger$ & 11.5 & $8.0-17.5$ & $9 \cdot 1$ & $7 \cdot 0-15 \cdot 5$ & 0.004 \\
\hline HOMA† & $2 \cdot 6$ & $1.7-4.5$ & $2 \cdot 2$ & $1.7-3.9$ & 0.065 \\
\hline Leptin (ng/ml)† & $16 \cdot 3$ & $8 \cdot 4-36 \cdot 0$ & $4 \cdot 3$ & $2 \cdot 2-8 \cdot 1$ & $<0.001$ \\
\hline Adiponectin $(\mathrm{ng} / \mathrm{ml}) \dagger$ & $12 \cdot 9$ & $9 \cdot 5-17 \cdot 7$ & $7 \cdot 9$ & $5 \cdot 7-11 \cdot 2$ & $<0.001$ \\
\hline \multicolumn{6}{|c|}{$\begin{array}{l}\text { FM, body fat mass; } S A T_{\text {total }} \text {, subcutaneous adipose tissue volume of the total body; } \mathrm{SAT}_{\text {trunk }} \text {, } \\
\text { subcutaneous adipose tissue volume of the trunk; } \mathrm{SAT}_{\text {arms }} \text {, subcutaneous adipose tissue } \\
\text { volume of the arms, SAT legs, subcutaneous adipose tissue volume of the legs; VAT, visceral } \\
\text { adipose tissue volume; FM:TAT, fat storage in adipose tissue; TAT, total adipose tissue; } \\
\text { HOMA, homeostasis model assessment. }\end{array}$} \\
\hline
\end{tabular}



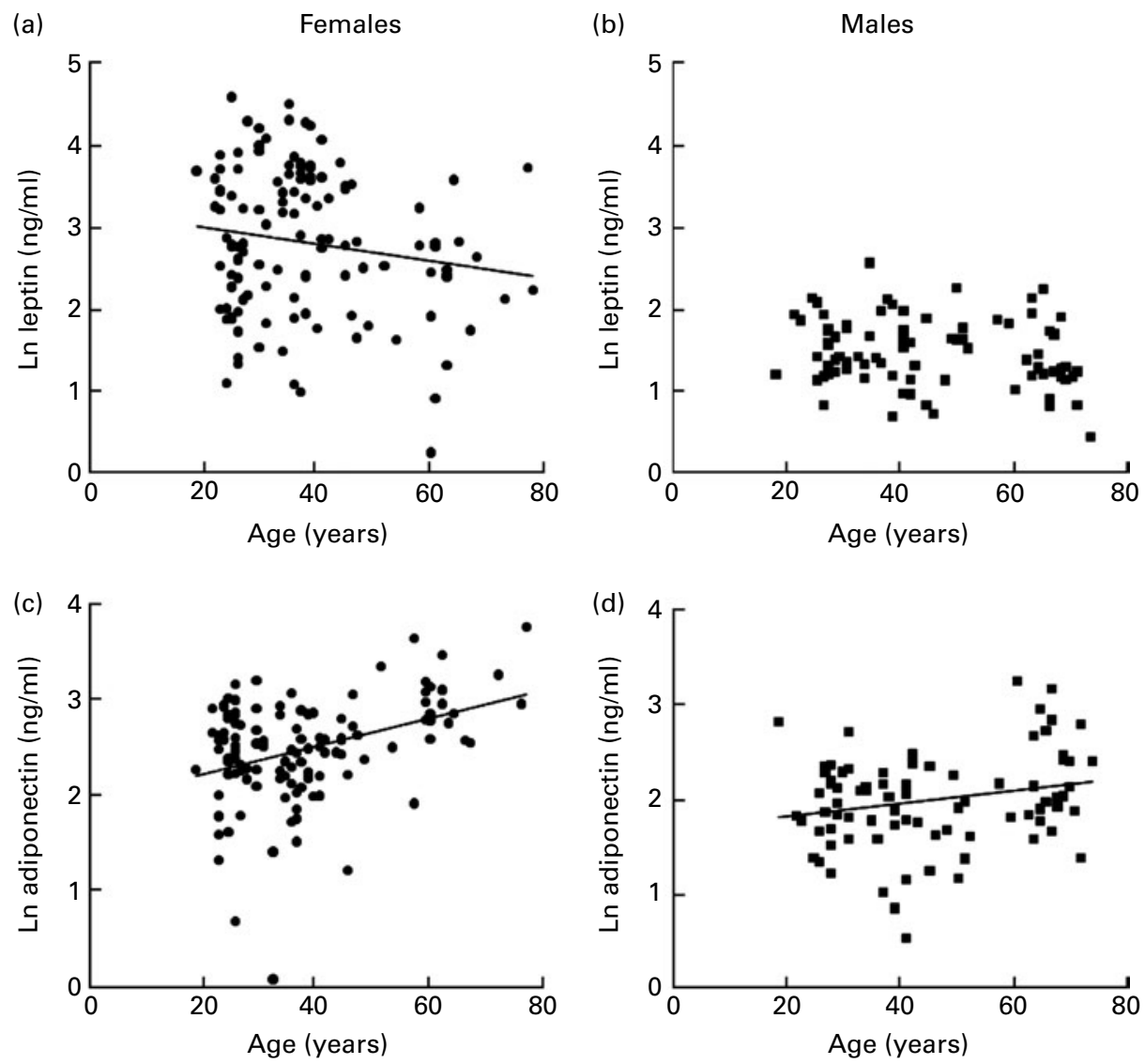

Fig. 1. Relationships between age and leptin ((a): $r-0.23, P=0.01$, (b): $r 0.16, P=0.16)$ and adiponectin levels ((c): $r 0.38, P<0.001,(d): r 0.23, P=0.04)$ in women $(a, c)$ and men $(b, d)$.

FM:TAT, body fat distribution and interaction terms between age and adiposity or body fat distribution (age $\times \% \mathrm{FM}$, age $\times$ VAT\%TAT and age $\times$ SAT $\%$ TAT) as independent variables, a model including age and \%FM explained $80.3 \%$ of the variance in leptin levels in women, with age $\times \% \mathrm{FM}$ explaining additional $1 \cdot 3 \%$. By contrast, age alone was not a significant predictor for leptin levels in men (Table 4). Including \% FM, FM:TAT, body fat distribution and interaction terms between age and adiposity or body fat distribution (age $\times \%$ FM, age $\times$ VAT $\%$ BV and age $\times$ SAT $\% B V)$ as independent variables in the prediction model, $\% \mathrm{FM}$ explained $76.6 \%$ of the variance, with age $\times \%$ FM explaining additional $1.7 \%$.

In contrast to leptin, adiponectin levels were positively correlated with age in both sexes (Table 2; Fig. 1). In women, adiponectin levels were inversely associated with regional SAT depots, whereas adiponectin adjusted for age correlated with $\mathrm{SAT}_{\text {trunk }}, \mathrm{SAT}_{\mathrm{arms}}$ and VAT. In men, adiponectin levels were inversely associated with \%FM, regional SAT depots, $\mathrm{SAT}_{\mathrm{arms}} \% \mathrm{TAT}$ and VAT (Table 3 ). Adjustment for age showed additional inverse associations between adiponectin and $\mathrm{SAT}_{\text {total }} \% \mathrm{TAT}, \mathrm{SAT}_{\text {legs }} \% \mathrm{TAT}$ and VAT\%TAT.

The results of a stepwise multiple regression analysis with adiponectin as the dependent variable and age, \%FM, FM:TAT, body fat distribution and interaction terms between age and adiposity or body fat distribution as independent variables are presented in Table 5. Age explained 5.1\%, $\mathrm{SAT}_{\text {trunk }}$
Table 2. Correlation coefficients and partial correlation coefficients adjusted for percentage of body fat mass (FM) for the relationships between age and adiposity, body fat distribution* and levels of adipokines stratified by sex ( $n$ 210)

(Correlation coefficients and partial correlation coefficient values)

\begin{tabular}{|c|c|c|c|c|}
\hline & \multicolumn{2}{|c|}{ Women ( $n$ 127) } & \multicolumn{2}{|c|}{ Men $(n 83)$} \\
\hline & $r$ & $P$ & $r$ & $P$ \\
\hline \multicolumn{5}{|c|}{ Correlation coefficients } \\
\hline$\% F M$ & 0.03 & 0.76 & 0.29 & 0.008 \\
\hline FM:TAT & 0.18 & 0.04 & 0.19 & 0.08 \\
\hline $\mathrm{SAT}_{\text {total }} \% \mathrm{TAT}$ & -0.53 & 0.07 & -0.62 & $<0.001$ \\
\hline $\mathrm{SAT}_{\text {trunk }} \% \mathrm{TAT}$ & 0.01 & 0.94 & -0.12 & 0.29 \\
\hline $\mathrm{SAT}_{\text {arms }} \% \mathrm{TAT}$ & 0.08 & 0.40 & -0.22 & 0.05 \\
\hline $\mathrm{SAT}_{\text {legs }} \% \mathrm{TAT}$ & -0.32 & $<0.001$ & -0.53 & $<0.001$ \\
\hline VAT\%TAT & 0.53 & $<0.001$ & 0.62 & $<0.001$ \\
\hline Ln leptin & -0.23 & 0.01 & $0 \cdot 16$ & 0.16 \\
\hline Ln adiponectin & 0.38 & $<0.001$ & 0.23 & 0.04 \\
\hline \multicolumn{5}{|c|}{ Partial correlation coefficients } \\
\hline FM:TAT & 0.23 & 0.04 & -0.04 & 0.72 \\
\hline $\mathrm{SAT}_{\text {total }} \% \mathrm{TAT}$ & -0.54 & $<0.001$ & -0.57 & $<0.001$ \\
\hline $\mathrm{SAT}_{\text {trunk }} \% \mathrm{TAT}$ & -0.01 & 0.94 & -0.17 & 0.14 \\
\hline $\mathrm{SAT}_{\text {arms }} \% \mathrm{TAT}$ & -0.09 & 0.31 & -0.10 & 0.37 \\
\hline SAT $T_{\text {legs }} \% T A T$ & -0.33 & $<0.001$ & -0.47 & $<0.001$ \\
\hline VAT\%TAT & 0.54 & $<0.001$ & 0.57 & $<0.001$ \\
\hline Ln leptin & -0.50 & $<0.001$ & -0.19 & 0.098 \\
\hline Ln adiponectin & 0.38 & $<0.001$ & 0.33 & 0.003 \\
\hline
\end{tabular}

FM:TAT, fat storage in adipose tissue; $\mathrm{SAT}_{\text {total, }}$ subcutaneous adipose tissue volume of the total body; TAT, total adipose tissue; SAT trunk, subcutaneous adipose tissue volume of the trunk; $S A T_{\text {arms }}$, subcutaneous adipose tissue volume of the arms, $\mathrm{SAT}_{\text {legs }}$, subcutaneous adipose tissue volume of the legs. * Adipose tissue volumes are given as \%TAT. 
Table 3. Correlation coefficients and partial correlation coefficients adjusted for age for the relationships between levels of leptin or adiponectin and body fat mass or body fat distribution* stratified by sex (Correlation coefficients and partial correlation coefficient values)

\begin{tabular}{|c|c|c|c|c|c|c|c|c|}
\hline & \multicolumn{4}{|c|}{ Women } & \multicolumn{4}{|c|}{ Men } \\
\hline & \multicolumn{2}{|c|}{ Unadjusted } & \multicolumn{2}{|c|}{ Age-adjusted } & \multicolumn{2}{|c|}{ Unadjusted } & \multicolumn{2}{|c|}{ Age-adjusted } \\
\hline & $r$ & $P$ & $r$ & $P$ & $r$ & $P$ & $r$ & $P$ \\
\hline \multicolumn{9}{|l|}{ Ln leptin } \\
\hline FM (\%) & 0.86 & $<0.001$ & $0 \cdot 89$ & $<0.001$ & 0.87 & $<0.001$ & 0.74 & $<0.001$ \\
\hline FM:TAT & 0.52 & $<0.001$ & 0.59 & $<0.001$ & 0.66 & $<0.001$ & 0.64 & $<0.001$ \\
\hline $\mathrm{SAT}_{\text {trunk }}$ & 0.81 & $<0.001$ & 0.81 & $<0.001$ & 0.75 & $<0.001$ & 0.77 & $<0.001$ \\
\hline $\mathrm{SAT}_{\mathrm{arms}}$ & 0.77 & $<0.001$ & 0.76 & $<0.001$ & 0.76 & $<0.001$ & 0.77 & $<0.001$ \\
\hline $\mathrm{SAT}_{\text {legs }}$ & 0.78 & $<0.001$ & 0.76 & $<0.001$ & 0.72 & $<0.001$ & 0.78 & $<0.001$ \\
\hline VAT & 0.46 & $<0.001$ & 0.58 & $<0.001$ & 0.67 & $<0.001$ & 0.69 & $<0.001$ \\
\hline $\mathrm{SAT}_{\text {total }} \% \mathrm{TAT}$ & 0.09 & 0.308 & -0.03 & 0.761 & -0.31 & 0.004 & -0.27 & 0.014 \\
\hline $\mathrm{SAT}_{\text {trunk }} \% \mathrm{TAT}$ & 0.44 & $<0.001$ & 0.46 & $<0.001$ & 0.17 & 0.135 & 0.19 & 0.087 \\
\hline $\mathrm{SAT}_{\text {arms }} \% \mathrm{TAT}$ & -0.36 & $<0.001$ & -0.36 & $<0.001$ & -0.43 & $<0.001$ & -0.43 & $<0.001$ \\
\hline $\mathrm{SAT}_{\text {legs }} \% \mathrm{TAT}$ & -0.23 & $<0.001$ & -0.32 & $<0.001$ & -0.37 & $<0.01$ & -0.34 & 0.002 \\
\hline VAT\%TAT & -0.09 & 0.308 & 0.03 & 0.761 & 0.31 & 0.004 & 0.27 & 0.014 \\
\hline \multicolumn{9}{|l|}{ Ln adiponectin } \\
\hline FM (\%) & -0.12 & $0 \cdot 180$ & -0.14 & 0.133 & -0.27 & 0.014 & -0.36 & 0.001 \\
\hline FM:TAT & 0.00 & 0.966 & -0.07 & 0.466 & -0.22 & 0.051 & -0.28 & 0.013 \\
\hline $\mathrm{SAT}_{\text {trunk }}$ & -0.23 & 0.009 & -0.20 & 0.031 & -0.30 & 0.006 & -0.31 & 0.005 \\
\hline $\mathrm{SAT}_{\text {arms }}$ & -0.26 & 0.003 & -0.23 & 0.013 & -0.22 & 0.046 & -0.23 & 0.036 \\
\hline $\mathrm{SAT}_{\text {legs }}$ & -0.21 & 0.02 & $-0 \cdot 13$ & 0.163 & -0.27 & 0.016 & -0.24 & 0.033 \\
\hline VAT & -0.04 & 0.667 & -0.19 & 0.035 & -0.29 & 0.008 & -0.45 & $<0.001$ \\
\hline $\mathrm{SAT}_{\text {total }} \% \mathrm{TAT}$ & 0.05 & 0.587 & -0.08 & 0.388 & $-0 \cdot 16$ & 0.142 & 0.40 & $<0.001$ \\
\hline $\mathrm{SAT}_{\text {trunk }} \% \mathrm{TAT}$ & $-0 \cdot 10$ & 0.260 & -0.12 & 0.198 & -0.06 & 0.600 & -0.03 & 0.768 \\
\hline $\mathrm{SAT}_{\text {arms }} \% \mathrm{TAT}$ & -0.04 & 0.684 & -0.07 & 0.459 & 0.31 & 0.005 & 0.38 & 0.001 \\
\hline $\mathrm{SAT}_{\text {legs }} \% \mathrm{TAT}$ & -0.02 & 0.778 & -0.17 & 0.059 & 0.15 & 0.182 & 0.33 & 0.003 \\
\hline VAT\%TAT & -0.14 & 0.130 & -0.08 & 0.388 & -0.16 & 0.142 & -0.40 & $<0.001$ \\
\hline
\end{tabular}

an additional $9 \cdot 1 \%$ and including VAT\%TAT in the model altogether explained $27 \cdot 2 \%$ of the variance in adiponectin levels in men. In women, age was the main predictor of adiponectin levels, explaining $14 \cdot 1 \%$ of its variance and $\mathrm{SAT}_{\text {trunk }}$ contributing to an additional $3.3 \%$ of explained variance.

Relationships between adipokines and indices of glucose metabolism independent of age and adiposity

Partial correlations adjusted for \%FM showed inverse relationships between age and insulin levels $(r-0.26$ for women and $r-0.30$ in men, both $P<0.01)$. There was also an inverse association between age and HOMA-IR in men $(r-0.25$,
$P<0.05)$ and a positive association between age and serum glucose levels in women $(r 0.39, P<0 \cdot 001)$.

Partial correlations adjusted for $\% \mathrm{FM}$, age and VAT\%TAT between levels of adipokines and parameters of glucose metabolism showed positive correlations between serum leptin and insulin $(r \quad 0.21, P<0.05)$, glucose $(r \quad 0.31$, $P<0.01)$ and HOMA-IR $(r 0.25, P<0.01)$ in women. By contrast, adiponectin levels showed inverse associations with parameters of glucose metabolism (insulin: $r-0 \cdot 31$, $P<0.001$; glucose: $r-0.19, P=0.03$; HOMA-IR: $r-0.32$, $P<0.001)$ in women. In men, no relationships between leptin or adiponectin levels and parameters of glucose metabolism were found.

Table 4. Regression models for the impact of age and other potential confounders on leptin levels in women ( $n$ 127) and men ( $n$ 83)

\begin{tabular}{|c|c|c|c|c|c|c|}
\hline & \multicolumn{3}{|c|}{ Non-standardised $\beta$-coefficients } & \multirow[b]{2}{*}{ Intercept } & \multirow[b]{2}{*}{$R^{2}$} & \multirow[b]{2}{*}{ SEE } \\
\hline & Age (years) & $\% F M$ & Age $\times \% F M$ & & & \\
\hline \multicolumn{7}{|l|}{ Women } \\
\hline Model 1 & -0.227 & - & & 1.952 & 0.052 & 0.50312 \\
\hline Model 2 & -0.252 & 0.867 & & 0.439 & 0.803 & 0.44051 \\
\hline Model 3 & -0.675 & 0.533 & 0.558 & 1.557 & 0.816 & 0.42760 \\
\hline \multicolumn{7}{|l|}{ Men } \\
\hline Model 1 & - & 0.874 & & -0.563 & 0.766 & 0.41717 \\
\hline Model 2 & - & 1.034 & -0.211 & -0.605 & 0.783 & 0.40255 \\
\hline
\end{tabular}

FM, body fat mass; age $\times \% \mathrm{FM}$, interaction between age and FM; $R^{2}$, coefficient of determination; SEE, standard error of estimate for the regression model. 
Table 5. Regression models for the impact of age and other potential confounders on adiponectin levels in women $(n 127)$ and men $(n 83)$

\begin{tabular}{|c|c|c|c|c|c|c|}
\hline & \multicolumn{3}{|c|}{ Non-standardised $\beta$-coefficient } & \multirow[b]{2}{*}{ Intercept } & \multirow[b]{2}{*}{$R^{2}$} & \multirow[b]{2}{*}{ SEE } \\
\hline & Age (years) & $\mathrm{SAT}_{\text {trunk }}$ & VAT\%TAT & & & \\
\hline \multicolumn{7}{|l|}{ Women } \\
\hline Model 1 & 0.375 & _- & - & 1.952 & 0.141 & 0.50312 \\
\hline Model 2 & 0.348 & -0.183 & - & $2 \cdot 194$ & 0.174 & 0.49544 \\
\hline \multicolumn{7}{|l|}{ Men } \\
\hline Model 1 & 0.226 & - & - & 1.736 & 0.051 & 0.51057 \\
\hline Model 2 & 0.307 & -0.301 & - & 2.076 & 0.142 & 0.48866 \\
\hline Model 3 & 0.514 & -0.270 & -0.462 & $2 \cdot 210$ & 0.272 & $0.4527 \varepsilon$ \\
\hline
\end{tabular}

\section{Discussion}

The present study shows that adiponectin levels increased with age in both sexes, whereas leptin decreased with age in women only. \%FM was the main predictor of leptin levels, but age added to the variance in serum leptin in women. By contrast, the variance in adiponectin levels was positively associated with age in both sexes, whereas independent and inverse contributions were found for truncal SAT (and VAT\%TAT in men). In women, leptin levels showed positive correlations and adiponectin inverse associations with parameters of glucose metabolism independent of age and body composition.

There was a significant decrease in leptin levels with age in women, whereas leptin did not decline with age in men (Table 2). These findings persist after controlling for \%FM and are in line with previous studies, showing an age-related decrease in leptin levels independent of $\mathrm{BMI}^{(11)}$ and $\% \mathrm{FM}^{(10,12)}$ in women and no effect of age in $\operatorname{men}^{(10-12,16)}$. By contrast, others found no association between age and (1) unadjusted leptin in women ${ }^{(18,25,26)}$ or (2) leptin levels normalised for \%FM measured by dual-energy X-ray absorptiometry or bioelectrical impedance ${ }^{(16,27)}$. Also, age-related increases in unadjusted leptin levels in women ${ }^{(9,27)}$ or \%FMadjusted leptin in men have been reported ${ }^{(27)}$. Some studies have found a decline in leptin only after adjusting for \% FM, whereas unadjusted leptin levels tended to increase with age $^{(12,27)}$. The different results could partly be explained by the cut-off chosen for separation of age groups. Some authors have shown an increase in unadjusted leptin levels up to the age of 60 years with a subsequent decrease ${ }^{(13,28)}$. We also found a decline in unadjusted leptin levels with age $\geq 60$ years in women, whereas partial correlation adjusted for $\% \mathrm{FM}$ revealed an inverse relationship between age and leptin levels already after the age of 45 years.

The present results show a significant age-related decrease in total $\mathrm{SAT}_{\text {total }} \% \mathrm{TAT}$, which was explained by the decline in $\mathrm{SAT}_{\text {legs }} \% \mathrm{TAT}$ (Table 2). Consistently, previous studies have found lower leg fat in older compared with younger women ${ }^{(29)}$ and men ${ }^{(30)}$. Because loss of gluteofemoral fat leads to a reduced propensity for storing fat away from the visceral compartment ${ }^{(31)}$, this may have contributed to the higher VAT\%TAT in older subjects (Table 2). These results are in line with previous studies ${ }^{(29,32,33)}$. According to the present results, the shift towards a central body fat distribution with age is explained by an increase in VAT and a concomitant decrease in $\mathrm{SAT}_{\text {legs }}$ at an unchanged $\mathrm{SAT}_{\text {trunk }}$.

In both sexes, \%FM was the main predictor of leptin levels. The interaction between \%FM and age had only a low impact on leptin levels in men, explaining $1.7 \%$ of the variance. In women, age alone explained $5.2 \%$ of the variance in leptin. This could be due to lower oestrogen production during and after menopause, because 17 $\beta$-oestradiol has been shown to increase leptin mRNA in rats ${ }^{(34)}$. Accordingly, Isidori et al. ${ }^{(11)}$ identified oestrogen as one factor that accounts for sex differences in leptin levels and could influence leptin production with age.

Using MRI-derived volumes of different adipose tissues and densitometry-derived FM, we found evidence for an increase of fat storage in adipose tissue with age in women (Table 2). Enlarged adipocytes showed a higher leptin secretion rate than smaller fat cells ${ }^{(23)}$. In agreement with this finding, we found associations between leptin levels and FM:TAT in both sexes (Table 3). However, FM:TAT as a measure of fat storage in adipose tissue has not been validated by biopsies. FM:TAT as a parameter of adipocyte size can be limited in the case of weight-loss-induced shrinkage of adipocytes. It is therefore possible that weight-reduced obese subjects may have a lower fat content at the same adipose tissue volume than never-obese, lean subjects with the same \%FM.

The age-related increase in adiponectin levels in both sexes (Fig. 1; Table 2) is in line with most studies ${ }^{(12,14,15,35)}$ but contrary to others who found a decrease $\mathrm{e}^{(36)}$ or no change ${ }^{(9,16)}$ in serum adiponectin levels with age. Because of (1) the age-related increase in \%FM and VAT\%TAT (Table 2) and (2) the inverse relationships between adiponectin and \% FM and VAT (Table 3 ) in men, serum adiponectin levels would have been expected to decrease with age. In agreement with the present results, other studies have reported inverse relationships between adiponectin and VAT measured by MRI or dual-energy X-ray absorptiometry ${ }^{(9,15,37)}$, or dual-energy $\mathrm{X}$-ray absorptiometry-derived trunk $\mathrm{FM}^{(9,37)}$. However, in the present study, age was the main predictor of adiponectin in women; $\mathrm{SAT}_{\text {trunk }}$ explained only $3 \%$ of the variance (Table 5). Thus, other factors, such as the age-related decline in testosterone and oestrogen levels, which have been shown 
to inhibit adiponectin production ${ }^{(38,39)}$, might have a higher impact on adiponectin than on body fat or fat distribution in women.

\section{Associations between leptin or adiponectin and parameters of glucose metabolism}

Adiponectin levels inversely correlated with the levels of insulin, glucose and HOMA-IR in women; this was independent of FM, individual fat depots and age. In line with previous results, these relationships were significant in women only ${ }^{(14,40)}$.

Leptin may adversely affect glucose metabolism. In fact, serum leptin levels (adjusted for adiposity and body fat distribution) showed positive associations with fasting insulin, glucose and HOMA-IR in women, but not in men. These relationships have been reported previously for women ${ }^{(41)}$ but also for $\operatorname{men}^{(8)}$. It is tempting to speculate that the observed age-related increase in serum adiponectin and decrease in serum leptin may protect against insulin resistance, and therefore explain the lower impact of $\% \mathrm{FM}$ on mortality in older subjects ${ }^{(6)}$.

\section{Strengths and limitations of the study}

One strength of the present study is the use of whole-body MRI in a study population covering a wide range of age and BMI. This method allows us to precisely differentiate between truncal SAT and VAT. In addition, we were able to measure volumes of adipose tissue instead of single-slice observations with computed tomography.

The present study has also several limitations. First, this is a cross-sectional rather than a longitudinal study. In addition, the age range of the present study population is limited. The oldest participants were 78 years old, so we could not investigate levels of adipokines or body fat distribution at advanced age. Also, we did not assess habitual physical activity, which may decrease leptin and increase adiponectin levels $^{(42)}$. We did not assess menopausal status, although sex hormones may have an impact on adipokine levels, and postmenopausal women were shown to have higher adiponectin levels and lower leptin levels than premenopausal women ${ }^{(12)}$.

The present results indicate that leptin levels should be normalised for \%FM only, because body fat distribution has a minor influence on serum leptin. Levels of adiponectin were inversely associated with body fat distribution ( $\mathrm{SAT}_{\text {trunk }}$ in both sexes and VAT\%TAT in men). When interpreting differences in adiponectin between people or populations, central fat distribution should be considered.

Although leptin levels are mainly explained by \%FM, the age-related decrease in leptin levels in women is partly independent of changes in adiposity. Higher serum adiponectin levels in older men and women occurred despite an agerelated increase in VAT and were thus considered independent of alterations in adiposity. The age-related changes in adipokine levels are opposite to each other. They might be due to changes in secretion or clearance and had a positive effect on parameters of glucose metabolism in women.

\section{Acknowledgements}

This study was funded by DFG Mü 714/8-3. The authors' contributions were as follows: A. B.-W. and M. J. M. designed the study; M. H. contributed to the MRI protocol; A. P. was responsible for the analysis of the blood samples; A. B.-W. and W. L. were involved in data collection; B. S. was involved in image segmentation; B. S. and A. B.-W. performed the data analyses; B. S., A. B.-W. and M. J. M. participated in the discussion of the data and the writing of the manuscript. There are no conflicts of interest.

\section{References}

1. Gabriely I \& Barzilai N (2001) The role of fat cell derived peptides in age-related metabolic alterations. Mech Ageing Dev 122, 1565-1576.

2. Kotani K, Tokunaga K, Fujioka S, et al. (1994) Sexual dimorphism of age-related changes in whole-body fat distribution in the obese. Int J Obes Relat Metab Disord 18, 207-202.

3. Boyko EJ, Fujimoto WY, Leonetti DL, et al. (2000) Visceral adiposity and risk of type 2 diabetes: a prospective study among Japanese Americans. Diabetes Care 23, 465-471.

4. Snijder MB, Dekker JM, Visser M, et al. (2004) Trunk fat and leg fat have independent and opposite associations with fasting and postload glucose levels: The Hoorn Study. Diabetes Care 27, 372-377.

5. Snijder MB, Visser M, Dekker JM, et al. (2005) Low subcutaneous thigh fat is a risk factor for unfavourable glucose and lipid levels, independently of high abdominal fat. The Health ABC Study. Diabetologia 48, 301-308.

6. Childers DK \& Allison DB (2010) The 'obesity paradox': a parsimonious explanation for relations among obesity, mortality rate and aging? Int J Obes (Lond) 34, 1231-1238.

7. Weyer C, Funahashi T, Tanaka S, et al. (2001) Hypoadiponectinemia in obesity and type 2 diabetes: close association with insulin resistance and hyperinsulinemia. J Clin Endocrinol Metab 86, 1930-1935.

8. Wannamethee SG, Tchernova J, Whincup P, et al. (2007) Plasma leptin: associations with metabolic, inflammatory and haemostatic risk factors for cardiovascular disease. Atherosclerosis 191, 418-426.

9. Ryan AS, Berman DM, Nicklas BJ, et al. (2003) Plasma adiponectin and leptin levels, body composition, and glucose utilization in adult women with wide ranges of age and obesity. Diabetes Care 26, 2383-2388.

10. Cnop M, Landchild MJ, Vidal J, et al. (2002) The concurrent accumulation of intra-abdominal and subcutaneous fat explains the association between insulin resistance and plasma leptin concentrations: distinct metabolic effects of two fat compartments. Diabetes 51, 1005-1015.

11. Isidori AM, Strollo F, More M, et al. (2000) Leptin and aging: correlation with endocrine changes in male and female healthy adult populations of different body weights. J Clin Endocrinol Metab 85, 1954-1962.

12. Marques-Vidal P, Bochud M, Paccaud F, et al. (2010) Distribution of plasma levels of adiponectin and leptin in an adult Caucasian population. Clin Endocrinol (Oxf) $\mathbf{7 2}$, $38-46$.

13. Ostlund RE Jr, Yang JW, Klein S, et al. (1996) Relation between plasma leptin concentration and body fat, gender, diet, age, and metabolic covariates. J Clin Endocrinol Metab 81, 3909-3913. 
14. Cnop M, Havel PJ, Utzschneider KM, et al. (2003) Relationship of adiponectin to body fat distribution, insulin sensitivity and plasma lipoproteins: evidence for independent roles of age and sex. Diabetologia 46, 459-469.

15. Koh SJ, Hyun YJ, Choi SY, et al. (2008) Influence of age and visceral fat area on plasma adiponectin concentrations in women with normal glucose tolerance. Clin Chim Acta 389, $45-50$.

16. Staiger H, Tschritter O, Machann J, et al. (2003) Relationship of serum adiponectin and leptin concentrations with body fat distribution in humans. Obes Res 11, 368-372.

17. Wiest R, Moleda L, Farkas S, et al. (2010) Splanchnic concentrations and postprandial release of visceral adipokines. Metabolism 59, 664-670.

18. Solin MS, Ball MJ, Robertson I, et al. (1997) Relationship of serum leptin to total and truncal body fat. Clin Sci (Lond) 93, 581-584.

19. Jurimae T, Sudi K, Jurimae J, et al. (2003) Relationships between plasma leptin levels and body composition parameters measured by different methods in postmenopausal women. Am J Hum Biol 15, 628-636.

20. Minocci A, Savia G, Lucantoni R, et al. (2000) Leptin plasma concentrations are dependent on body fat distribution in obese patients. Int J Obes Relat Metab Disord 24, 1139-1144.

21. Siri WE (1993) Body composition from fluid spaces and density: analysis of methods. 1961. Nutrition 9, 480-491, discussion 480, 492.

22. Spalding KL, Arner E, Westermark PO, et al. (2008) Dynamics of fat cell turnover in humans. Nature 453, 783-787.

23. Jernas M, Palming J, Sjoholm K, et al. (2006) Separation of human adipocytes by size: hypertrophic fat cells display distinct gene expression. FASEB J 20, 1540-1542.

24. Matthews DR, Hosker JP, Rudenski AS, et al. (1985) Homeostasis model assessment: insulin resistance and beta-cell function from fasting plasma glucose and insulin concentrations in man. Diabetologia 28, 412-419.

25. Castracane VD, Kraemer RR, Franken MA, et al. (1998) Serum leptin concentration in women: effect of age, obesity, and estrogen administration. Fertil Steril 70, 472-477.

26. Douchi T, Iwamoto I, Yoshimitsu N, et al. (2002) Differences in leptin production by regional fat mass in postmenopausal women. Endocr J 49, 413-416.

27. Baumgartner RN, Waters DL, Morley JE, et al. (1999) Agerelated changes in sex hormones affect the sex difference in serum leptin independently of changes in body fat. Metabolism 48, 378-384.

28. Perry HM III, Morley JE, Horowitz M, et al. (1997) Body composition and age in African-American and Caucasian women: relationship to plasma leptin levels. Metabolism 46, 1399-1405.
29. Douchi T, Yamamoto S, Yoshimitsu N, et al. (2002) Relative contribution of aging and menopause to changes in lean and fat mass in segmental regions. Maturitas 42, 301-306.

30. Borkan GA, Hults DE, Gerzof SG, et al. (1985) Comparison of body composition in middle-aged and elderly males using computed tomography. Am J Phys Anthropol 66, 289-295.

31. van Pelt RE, Jankowski CM, Gozansky WS, et al. (2005) Lower-body adiposity and metabolic protection in postmenopausal women. J Clin Endocrinol Metab 90, 4573-4578.

32. Shen W, Punyanitya M, Silva AM, et al. (2009) Sexual dimorphism of adipose tissue distribution across the lifespan: a cross-sectional whole-body magnetic resonance imaging study. Nutr Metab (Lond) 6, 17.

33. Zamboni M, Armellini F, Harris T, et al. (1997) Effects of age on body fat distribution and cardiovascular risk factors in women. Am J Clin Nutr 66, 111-115.

34. Murakami T, Iida M \& Shima K (1995) Dexamethasone regulates obese expression in isolated rat adipocytes. Biochem Biophys Res Commun 214, 1260-1267.

35. Isobe T, Saitoh S, Takagi S, et al. (2004) [Adiponectin levels and coronary risk factors in the elderly]. Nihon Ronen Igakkai Zasshi 41, 328-333.

36. Vilarrasa N, Vendrell J, Maravall J, et al. (2005) Distribution and determinants of adiponectin, resistin and ghrelin in a randomly selected healthy population. Clin Endocrinol (Oxf) 63, 329-335.

37. Snijder MB, Flyvbjerg A, Stehouwer CD, et al. (2009) Relationship of adiposity with arterial stiffness as mediated by adiponectin in older men and women: The Hoorn Study. Eur J Endocrinol 160, 387-395.

38. Combs TP, Berg AH, Rajala MW, et al. (2003) Sexual differentiation, pregnancy, calorie restriction, and aging affect the adipocyte-specific secretory protein adiponectin. Diabetes 52, 268-276.

39. Nishizawa H, Shimomura I, Kishida K, et al. (2002) Androgens decrease plasma adiponectin, an insulin-sensitizing adipocyte-derived protein. Diabetes 51, 2734-2741.

40. Salas-Salvado J, Granada M, Bullo M, et al. (2007) Plasma adiponectin distribution in a Mediterranean population and its association with cardiovascular risk factors and metabolic syndrome. Metabolism 56, 1486-1492.

41. Paz-Filho G, Esposito K, Hurwitz B, et al. (2008) Changes in insulin sensitivity during leptin replacement therapy in leptin-deficient patients. Am J Physiol Endocrinol Metab 295, E1401-E1408.

42. de Salles BF, Simao R, Fleck SJ, et al. (2010) Effects of resistance training on cytokines. Int J Sports Med 31, 441-450. 